\title{
[

\section{IMPLEMENTASI AUGMENTED REALITY SEBAGAI MEDIA PEMBELAJARAN BANGUN RUANG BERBASIS ANDROID (STUDI KASUS: SD ANUGRAH PLUS PEKANBARU)}

\author{
Yulisman $^{1}$, Hendry Fonda ${ }^{2}$, Andriana Kiki Yolanda ${ }^{3}$ \\ ${ }^{1,2,3}$ Sistem Informasi, STMIK Hang Tuah Pekanbaru \\ Email : \\ yulismanaziera27@gmail.com ${ }^{1}$,fondaanda@gmail.com ${ }^{2}$, andrianakikiyolanda27@gmail.com ${ }^{3}$
}

\begin{abstract}
The application of information and communication technology in education is very helpful in teaching and learning activities, one of which is the use of smartphone technology as a learning medium in education, namely the learning system in subjects. Almost all subjects can take advantage of smartphone technology as a learning medium, especially mathematics, and especially for discussion of 3dimensional building blocks. The purpose of building this system is to assist teachers in explaining the form of 3 dimensional shapes to students so that students are interested in learning to build spaces using smartphone technology. The research method uses the Waterfall model system development model. The system is built by implementing Augmented reality using Google SketchUp as 3D modeling, Vuforia and Unity as a platform for the development and creation of 3dimensional images and space-building marker images used for making Augmented reality implementation applications, and the programming language is Java with JDK and SDK. The result is that the system has been successfully built and has been running well and can be used according to the needs of users (teachers and students) and the conclusion is that the Augmented reality system makes it easy for teachers to explain real spaces to students and attracts students' interest in learning shapes. geometry. Rating from users of the system as a whole was $86.6 \%$ (very good).
\end{abstract}

Keywords: Augmented reality, android, build space 3D, smartphone.

\begin{abstract}
Abstrak
Penerapan teknologi informasi dan komunikasi pada bidang pendidikan sangat membantu dalam kegiatan belajar dan mengajar, salah satunya pemanfaatan teknologi smartphone sebagai media pembelajaran dalam bidang pendidikan yaitu dengan sistem pembelajaran pada mata pelajaran. Hampir semua mata pelajaran bisa memanfaatkan teknologi smartphone sebagai media pembelajaran terutama mata pelajaran matematika, dan khususnya untuk pembahasan pelajaran bangun ruang 3 dimensi. Tujuan dibangunnya sistem ini adalah untuk membantu guru dalam menjelaskan bentuk bangun ruang secara 3dimensi kepada siswa agar siswa tertarik untuk belajar bangun ruang dengan menggunakan teknologi smartphone. Metode penelitian dengan menggunakan model pengembangan sistem model Waterfall. Sistem dibangun dengan menerapkan Augmented reality menggunakan Google SketchUp sebagai pemodelan 3D, vuforia dan Unity sebagai flatform untuk pengembangan dan pembuatan gambar 3dimensi dan gambar marker bangun ruang yang digunakan untuk pembuatan aplikasi implementasi Augmented reality, serta bahasa pemrograman adalah Java dengan JDK dan SDK. Hasilnya sistem sukses dibangun dan telah berjalan dengan baik dan dapat digunakan sesuai dengan kebutuhan user (guru dan siswa) dan diperoleh kesimpulan bahwa sistem Augmented reality bangun ruang ini memberikan kemudahan bagi guru dalam menjelaskan bangun ruang secara real kepada siswa dan menarik minat siswa dalam mempelajari bentuk bangun ruang. Penilaian dari pengguna sistem secara keseluruhan $86,6 \%$ (sangat baik).
\end{abstract}

Keywords: Augmented reality, android, bangun ruang 3D, smartphone.

https://doi.org/10.33060/JIK/2020/Vol9.Iss2.163 


\section{PENDAHULUAN}

Tuntutan globalisasi memaksa dunia pendidikan untuk selalu siap dan senantiasa menyesuaikan dengan perkembangan teknologi informasi dan komunikasi terhadap upaya dalam meningkatkan kualitas pendidikan, terutama penyesuaian penggunaannya bagi dunia pendidikan khususnya dalam proses pembelajaran . Teknologi informasi dan komunikasi merupakan aplikasi ilmu dan keahlian yang dimanfaatkan pengguna dalam menyampaikan pesan atau informasi dengan maksud dapat memberikan bantuan dalam menyelesaikan persoalan pengguna (kegiatan sosial) agar tercapai tujuan komunikasi . Penerapan teknologi informasi dan komunikasi digunakan untuk membantu kegiatan proses belajar dan mengajar. Teknologi yang digunakan seperti penggunaan komputer, internet, e-learning, media sosial, simulasi pembelajaran dan yang terbaru seperti penggunaan perangkat mobile, aplikasi game, dunia virtual, dan Augmented Reality (AR)

Dilansir dari kominfo.go.id menyebutkan perkembangan teknologi informasi dan komunikasi yang signifikan beberapa tahun terakhir adalah teknologi smartphone, terutama di Indonesia tumbuh dengan pesat. Hasil riset yang pernah dilakukan oleh Lembaga riset digital marketing Emarketer pada tahun 2018 memperkirakan pengguna smartphone yang aktif di Indonesia lebih dari 100 juta orang. Seperti dilansir dari kompas.com bahwa menyebutkan perkembangan teknologi smartphone juga berimbas pada dunia pendidikan di Indonesia, seperti dari hasil penelitian yang dilakukan oleh Cambridge International melalui Global Education Census menunjukan siswa Indonesia sangat akrab dengan teknologi terutama smartphone, dimana pelajar Indonesia yang menggunakan smartphone di dalam pelajaran kelas $67 \%$, dan bahkan lebih sering untuk mengerjakan pekerjaan rumah (81\%), serta ini dapat dibandingkan dengan pelajar di negara-negara lain, termasuk di negara-negara yang lebih maju. Smartphone merupakan telepon seluler dengan kemampuan lebih, mulai dari resolusi, fitur, hingga komputasi termasuk adanya sistem operasi mobile di dalamnya. Menurut Kotler Smartphone dapat digunakan sebagai sarana pembelajaran dimana melalui smartphone seseorang dapat mempelajari hal-hal baru melalui isi atau pesan yang disalurkan .

Pemanfaatan teknologi smartphone dalam bidang pendidikan bisa diterapkan sebagai media pembelajaran yang interaktif. Media pembelajaran secara umum adalah alat bantu yang wajib ada agar proses belajar dan mengajar berjalan lancar. Media pembelajaran adalah merupakan media yang berfungsi sebagai pendukung dan faktor utama dalam kesuksesan proses pembelajaran di institusi pendidikan terutama sekolah, karena bisa membantu tenaga pengajar dalam memberikan materi dan informasi kepada peserta didik begitu juga sebaliknya .
Hampir semua mata pelajaran disekolah bisa diterapkan dengan teknologi smartphone agar lebih interaktif dan menarik, salah satunya mata pelajaran Matematika, da dari sekian banyak materi dan tema pada mata pelajaran matematika, peneliti lebih membahas materi tentang bangun ruang pada penelitian ini. Hasil survey Programme for Internatioal Student Assessment (PISA) 2000/2001 menyebutkan bahwa pelajar Indonesia masih kurang dalam pemahaman tentang bangun ruang, terutama dalam mempelajari dan perhitungan ruang dan bentuk Sebagai gambaran berdasarkan obeservasi yang telah lakukan siswa mengalami kesulitan dalam membayangkan dan mengimajinasikan suatu balok yang berongga di dalamnya. Pelajaran bangun ruang pada siswa SD kelas 6 (enam) membutuhkan visualisasi atau model obyek-obyek bangun ruang secara nyata atau kelihatan agar siswa dapat memahami dan mengerti obyek bangun ruang seperti kubus, balok, prisma, tabung, kerucut, limas, dan bola dengan baik. Hal ini juga didukung oleh teori yang dikemukakan oleh Menurut teori kognitif Piaget, perkembangan kognitif anak usia dasar berada pada dua fase yaitu pertama fase operasional konkret (7-11 tahun) adalah fase dimana anak sudah dapat memfungsikan akalnya untuk berfikir logis, rasional dan objektif, tetapi terhadap objek yang bersifat konkret. Kedua fase operasional formal (1112 tahun ke atas) adalah fase dimana anak sudah dapat memikirkan sesuatu yang akan atau mungkin terjadi (hipotesis) dan sesuatu bersifat abstrak"

Perkembangan teknologi smartphone yang terus meningkat media pembelajaran yang statis dapat berubah menjadi media pembelajaran yang lebih dinamis dan dapat menampilkan visualisasi obyek bangun ruang secara konkret. Salah satu teknologi yang dapat dimanfaatkan adalah teknologi augmented reality pada android. Menurut Azuma (2007) Augmented reality merupakan sebagai penggabungan benda benda nyata dan maya di lingkungan nyata, berjalan secara interaktif dalam waktu nyata dan terdapat integrasi dan maya dimungkinkan dengan teknologi tampilan yang sesuai, interaktivitas dimungkinkan melalui perangkat-perangkat input tertentu, dan integrasi yang baik . Dengan memanfaatkan teknologi augmented reality dan smartphone android yang dikombinasikan langsung dengan materi dari buku cetak, obyek bangun ruang dapat divisualisasikan dengan konkret melalui pemodelan virtual tiga dimensi yang mirip dengan benda aslinya. Aplikasi sebagai media pembelajaran matematika bangun ruang berbasis android dengan memanfaatkan teknologi augmented reality dapat menjadi alternatif untuk membantu siswa dalam memahami berbagai obyek bangun ruang secara konkret. Media ini diharapkan dapat menambah daya tarik siswa untuk belajar dengan perpaduan interaksi manusia dan komputer yang variatif yakni penggabungan pemodelan 3D geometri pada aplikasi android dengan materi di buku cetak. Sistem pembelajaran 
Matematika kelas 6 mengenai bangun ruang di SD Anugrah Plus Pekanbaru saat ini masih menggunakan metode pembelajaran konvensional yaitu pembelajaran yang terpusat pada guru dengan media pembantu seperti buku yang dirasa kurang menarik minat siswa. Dan biasanya siswa hanya dapat melihat dan membayangkan bentuk bangun ruang melalui buku yang berbentuk 2 Dimensi. Hal ini cukup menyulitkan guru dalam menjelaskan kepada siswa bagaimana bentuk real bangun ruang karena tidak adanya alat pembantu secara real.

Penerapan teknologi augmented reality menggunakan smartphone sebagai media pembelajaran pernah dilakukan penelitian sebelum oleh peneliti sebelumnya, dan dimana hasil dari penelitian tersebut menyatakan bahwa Augmented Reality, guru dapat membuat media pembelajaran yang menyenangkan, interaktif, dan mudah digunakan serta dapat menggantikan modul pembelajaran dalam bentuk virtual atau maya namun tetap seperti modul aslinya. Penelitian yang lain juga menyatakan hasilnya Augmented Reality dapat menampilkan objek berupa organ dalam pencernaan manusia secara virtual 3D dengan menggunakan gambar marker untuk dideteksi oleh kamera pada smartphone android akan menampilkan objek 3D sistem pencernaan, sehingga pengguna aplikasi dapat mengamati bagaimana bentuk organ-organ sistem pencernaan secara realtime.

\section{METODE PENELITIAN}

Metode penelitian merupakan proses ilmiah yang dilakukan oleh peneliti untuk memperoleh suatu pemikiran ilmiah dengan langkah-langkah yang telah ditentukan dan terstruktur untuk mencapai tujuan utama yaitu kepentingan khalayak umum. Metode penelitian dalam bidang teknologi informasi dan komunikasi dituangkan dalam sebuah model, model tersebut terdiri dari langkah-langkah yang terstruktur terapkan peneliti dalam pembuatan dan pengembangan suatu sistem atau aplikasi yang sering disebut SDLC (Systems Development Life Cycle). Model SDLC (Systems Development Life Cycle) yang diterapkan dalam penelitian ini adalah model Waterfall. Model ini melakukan pendekatan secara sistematis dan berurutan. Disebut dengan waterfall karena tahap demi tahap yang dilalui harus menunggu selesainya tahap sebelumnya dan berjalan berurutan. Model waterfall adalah model klasik yang bersifat sistematis, berurutan dalam membangun software . Berikut fase dari model waterfal menurut Pressman:

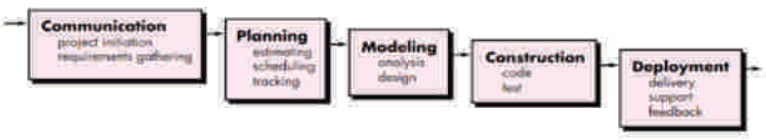

Gambar 1. Model Waterfall (Pressman, 2012)
Selanjutnya setelah menentukan model pembuatan dan pengembangan aplikasi, peneliti mulai melakukan proses penelitian sesuai dengan fase yang ada pada model waterfall tersebut yang dimulai dari :

\section{Communication (Project Initiation \& Requirements Gathering)}

Sebelum melanjutkan proses penelitian dan pekerjaan yang bersifat teknis, sangat dibutuhkan adanya komunikasi yang intens dengan pengguna (user) demi memahami dan mencapai tujuan yang ingin dicapai. Hasil dari komunikasi tersebut adalah inisialisasi proyek yang dimulai menganalisis permasalahan yang dihadapi oleh pengguna dan mengumpulkan data-data yang terkait dengan membangun aplikasi dan diperlukan, serta membantu mendefinisikan fitur dan fungsi aplikasi/sistem. Tahapan ini juga ada tiga langkah utama yang dilakukan oleh peneliti, berikut langkah-langkah tersebut:

a. Observasi, Tahap observasi ini peneliti melakukan pengamatan langsung ke studi kasus di SD Anugrah Plus Pekanbaru untuk mengetahui bagaimana proses pembelajran berlangsung mengumpulkan data-data yang dibutuhkan untuk membangun aplikasi Implementasi Augmented Reality sebagai media pembelajaran bangun ruang berbasis android.

b. Wawancara, tahapan berikutnya adalah proses wawancara, dimana peneliti melakukan wawancara dengan staff guru SD Anugrah Plus Pekanbaru. Wawancara ini dilakukan untuk memperoleh informasi yang lebih mendalam tentang proses pembelajaran dan media yang digunakan dalam pembelajaran untuk pembuatan aplikasi Implementasi Augmented Reality sebagai media pembelajaran bangun ruang berbasis android.

c. Studi Pustaka, tahapan studi pustaka ini peneliti melakukan tinjauan umum terhadap buku-buku, artikel, majalah, modul dan browsing di internet serta sumber lainnya yang bisa dijadikan teori pendukung yang tema berhubungan dengan tema dan permasalahan penelitian.

\section{Planning(Estimating, Scheduling, Tracking)}

Tahap berikutnya adalah tahapan perencanaan yang menjelaskan tentang estimasi, dimana estimasi ini berkaitan dengan perencanaan biaya yang akan dibutuhkan selama membangun aplikasi dari tahap komunikasi sampai dengan tahap implementasi dan estimsi juga berkaitan dengan tugastugas teknis yang akan dilakukan, resiko-resiko yang dapat terjadi, sumber daya yang dibutuhkan dalam membangun aplikasi, serta produk kerja yang ingin dihasilkan. Tahap ini sangat diperlukan penyusunan jadwal kerja yang akan dilakukan oleh sumber daya yang terlibat, terutama sumber daya manusia (SDM), dan yang terakhir yang wajib dilakukan tahap ini adalah tracking proses pengerjaan sistem dari tahap awal sampai akhir.

\section{Modeling (Analysis \& Design)}

Tahap Modeling (pemodelan) yang terdiri dari analisis dan perancangan sistem yang akan dibuat. Secara umum permodelan berkaitan dengan pemodelan arsitektur sistem yang

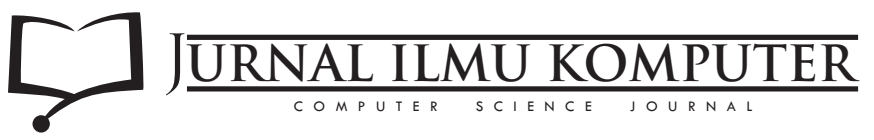


berfokus pada perancangan struktur data, arsitektur aplikasi, tampilan user interface, dan algoritma program. Tujuannya pemodelan ini untuk lebih memahami gambaran besar dari apa yang akan dikerjakan dalam pembuatan aplikasi Implementasi Augmented Reality sebagai media pembelajaran bangun ruang berbasis android. Berikut tahapan pemodelan yang terdiri dari beberapa langkah:

a. Perancangan data

Data yang dibutuhkan dalam pembuatan aplikasi aplikasi implementasi augmented reality sebagai media pembelajaran bangun ruang berbasis android ini dari buku pelajaran kelas 6 SD Anugrah Plus Pekanbaru dan artikel yang berkaitan dengan materi bangun ruang.

b. Perancangan pengguna

Pengguna (user) merupakan bagian dari terpenting yang mengoperasikan aplikasi. Pengguna dari aplikasi implementasi augmented reality sebagai media pembelajaran bangun ruang berbasis android adalah guru dan siswa kelas 6 SD Anugrah Plus Pekanbaru.

c. Perancangan Model Aplikasi

Perancangan model aplikasi merupakan bagian dari pemodelan dan perancangan model aplikasi ini untuk menggambarkan hubungan aplikasi dengan pengguna (user) aplikasi Implementasi Augmented Reality sebagai media pembelajaran bangun ruang berbasis android. Perancangan model aplikasi yang digunakan adalah model UML (Unified modeling language). Model UML (Unified modeling language) merupakan suatu bahasa yang berfungsi sebagai alat untuk memvisualisasikan dan mendokumentasikan hasil analisa dan desain yang berisi sintak dalam memodelkan sistem secara visual. Juga merupakan satu kumpulan konvensi pemodelan yang digunakan untuk menentukan atau menggambarkan sebuah sistem software yang terkait dengan objek. Perancangan pemodelan aplikasi augmented reality sebagai media pembelajaran bangun ruang berbasis android menggunakan beberapa diagram yakni Use Case Diagram, Sequence Diagram, activity diagram, dan perancangan user interface. Berikut perancangan model diagram implementasi Augmented Reality sebagai media pembelajaran bangun ruang berbasis android pada SD Anugrah Plus Pekanbaru:

\section{1) Use Case Diagram}

Use case diagram atau diagram use case merupakan pemodelan atau deskripsi fungsi dalam bentuk teks dan simbol untuk mendefnisikan aktivitas aktor dengan sebuah perangkat lunak atau interaksi antara satu atau lebih aktor yang akan dibangun. Berikut perancangan use case diagram aplikasi Implementasi Augmented Reality sebagai media pembelajaran bangun ruang berbasis android pada SD Anugrah Plus Pekanbaru:

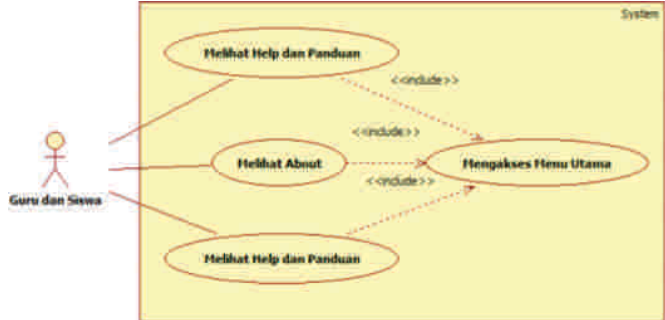

Gambar 2. Use Case Diagram Augemented Reality Bangun Ruang Berbasis Android

\section{2) Sequence diagram}

Menurut Satzinger (2010) Sequence diagram adalah diagram yang digunakan untuk mendefinisikan masukan dan keluaran sejumlah objek serta urutan komunikasi antara pengguna dan perangkat lunak pada suatu titik objek dan terjadi eksekusi use case . Perancangan Sequence diagram digunakan untuk dapat mengetahui alur proses dan interaksi antara objek yang terdapat pada aplikasi implementasi augemented reality sebagai media pembelajaran bangun ruang berbasis android. Di bawah ini merupakan rancangan sequence diagram yang akan dibangun:

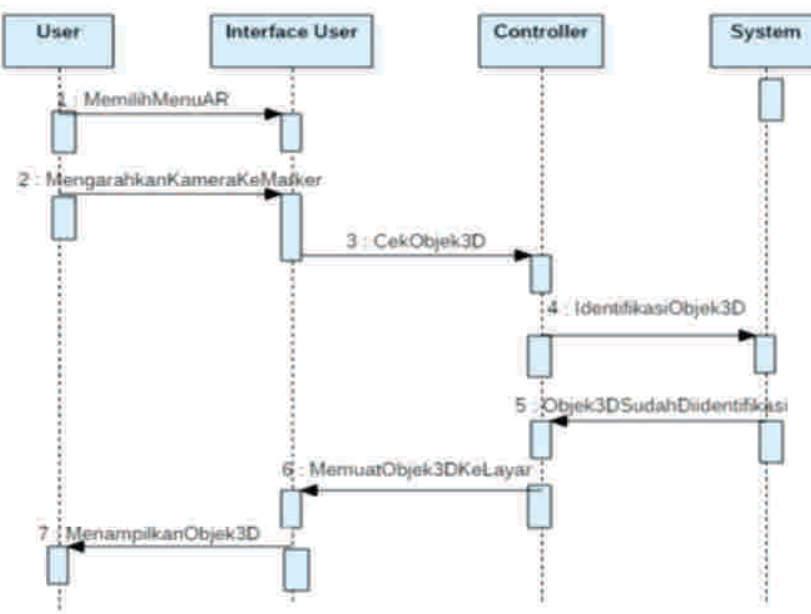

\section{Gambar 3. Sequence Diagram Augemented Reality Bangun Ruang Berbasis Android}

\section{3) Activity Diagram}

Perancangan Activity Diagram (diagram aktivitas) yang menggambarkan bagaimana fungsional aplikasi pada setiap aktivitas yang dilakukan pengguna. Activity Diagram adalah Menggambarkan rangkaian aliran dari aktivitas, digunakan untuk mendeskripsikan aktifitas yang dibentuk dalam suatu operasi sehingga dapat juga digunakan untuk aktifitas lainnya seperti use case atau interaksi . Perancangan pemodelan Activity Diagram (diagram aktifitas) bertujuan menunjukkan aliran kerja aplikasi atau menggambarkan aliran kejadian saat aplikasi digunakan oleh pengguna. Berikut perancangan pemodelan dari Activity Diagram (diagram aktifitas) Augmented Reality (AR) Bangun Ruang Berbasis Android yang akan dibangun: 
a) Activity Diagram Menu Utama

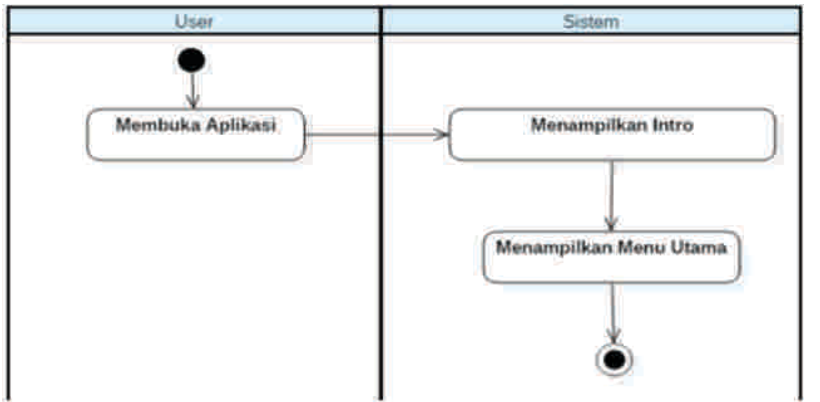

Gambar 4. Activity Diagram Menu Utama Augemented Reality Bangun Ruang Berbasis Android

Activity Diagram di atas, menjelaskan aktifitas user/ pengguna dalam membuka dan menampilkan menu utama pada aplikasi Implementasi Augmented Reality (AR) Bangun Ruang berbasis Android.

b) Activity Diagram Menu Augmented Reality Bangun Ruang

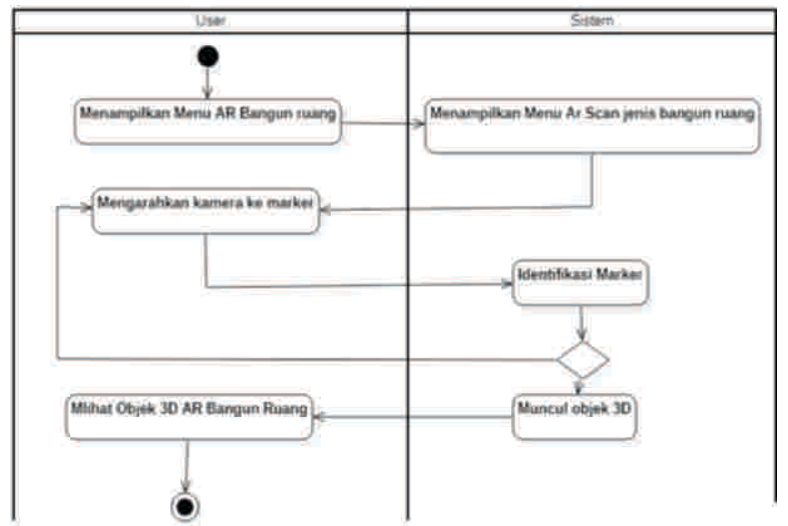

Gambar 5. Activity Diagram Memilih Menu Augmented Reality Bangun Ruang

\section{C.Perancangan User Interface}

Perancangan User Interface (antar muka) pada aplikasi Implementasi Augmented Reality (AR) bangun ruang berbasis Android ini dirancang dengan sederhana sehingga user/pengguna yang menggunakan aplikasi ini dapat menggunakannya dengan mudah. Perancangan User Interface (antar muka) berdasarkan kebutuhkan dan saran dari pengguna terutama guru, sebab guru akan lebih banyak porsinya dalam menggunakan aplikasi ini yang akan menjelaskan kepada siswa baik dalam peggunaan aplikasi maupun dalam menjelaskan bangun ruang itu sendiri.

4. Construction (Code \& Test)

Tahapan Construction ini merupakan proses pendefinisian model desain koding bahasa yang dapat dimengerti oleh mesin elektornik terutama smartphone yang berbasis android. Kode yang digunakan adalah bahasa Pemrograman Java dengan tool JDK (Java Development Kit) dan SDK sebagai perangkat lunak pengembangan fitur-fitur flatform Android. Pembuatan marker untuk merubah bangun ruang ke gambar 3Dimensi menggunakan aplikasi vuforia. Vuforia merupakan Augmented Reality Software Development Kit (SDK) untuk perangkat mobile yang memungkinkan pembuatan aplikasi Augmented reality.
Vuforia menggunakan teknologi Computer Vision untuk mengenali dan melacak gambar planar (Target Image) dan objek 3D sederhana, seperti kotak, secara real-time. Fitur yang digunakan pada aplikasi adalah AR camera, Image Target dan Extended Tracking (Hanief \& Masurya, 2014). Vuforia juga menyediakan beberapa jenis database yakni Device, dan Cloud. Pembuatan marker pada vuforia dengan memilih VuMark yang nanti akan terbentuk marker berbentuk unik.

Setelah marker bangun ruang terbentuk, selanjutnya marker bangun ruang tersebut dirubah ke 3Dimensi melalui Smartphone menggunakan aplikasi Unity 3D. Unity 3D Unity 3D adalah sebuah game engine yang berbasis cross-platform. Unity 3D merupakan seb Unity 3D adalah sebuah game engine yang berbasis cross-platform. Aplikasi ini dapat digunakan untuk membuat sebuag game multi-platform yang bisa digunakan pada perangkat komputer, android, iPhone, PS 3, dan X-BOX. Unity pertama kali dikeluarkan untuk Mac OS X pada saat konferensi dunia developer apple (Apple's Worldwide Developers Conference) tahun 2005. Fitur scripting yang disediakan mendukung 3 bahasa pemrograman yaitu, JavaScript, C\#, dan Boo(Mahendra, 2016). Untuk membuat sebuah karya pada unity, terdapat beberapa hal penting yang perlu diketahui, di ataranya Project, Toolbar, Scene, Inspector, dan Hierarchy.

Setelah pengkodean dan pembuatan aplikasi selesai, dilakukan pengujian terhadap aplikasi dan juga kode yang dituangkan dalam bahasa pemrograman yang sudah dibuat. Tujuannya untuk menemukan kesalahan yang mungkin terjadi untuk nantinya diperbaiki. Metode pengujian yang digunakan pada aplikasi Augemented Reality sebagai media pembelajaran bangun ruang berbasis Android adalah metode black box. Metode pengujian black box Merupakan pengujian perangkat lunak yang merupakan tes fungsionalitas dari aplikasi yang tidak mengacu pada struktur internal atau tidak membutuhkan pengetahuan khusus pada kode program aplikasi dan pengetahuan pemrograman. Pengujian berada di ranah spesifikasi dan persyaratan yang seharusnya. Pengujian ini menggunakan deskripsi eksternal perangkat lunak termasuk spesifikasi, persyaratan dan desain untuk menurunkan uji kasus (pengujian) (Febiharsa, Sudana, \& Hudallah, 2018). Berikut hasil dari pengujian aplikasi implementasi augemented reality sebagai media pembelajaran bangun ruang berbasis Android:

Tabel 1. Hasil Pengujian Black Box

\begin{tabular}{|c|c|c|c|c|}
\hline No & $\begin{array}{c}\text { Skenari } \\
\text { o } \\
\text { Pengujia } \\
\text { n }\end{array}$ & Test Case & $\begin{array}{c}\text { Hasil Yang di } \\
\text { Harapkan }\end{array}$ & $\begin{array}{c}\text { Hasil } \\
\text { Uji }\end{array}$ \\
\hline 1 & $\begin{array}{l}\text { User } \\
\text { mengklik } \\
\text { icon } \\
\text { aplikasi di } \\
\text { smartphone }\end{array}$ & $\begin{array}{l}\text { Tampilan awal } \\
\text { aplikasi yang } \\
\text { pertama kali } \\
\text { muncul pada } \\
\text { saat dijalankan }\end{array}$ & 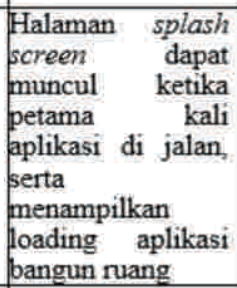 & $\begin{array}{l}\text { Sesuai } \\
\text { Harapan } \\
\text { (Valid) }\end{array}$ \\
\hline
\end{tabular}




\begin{tabular}{|c|c|c|c|c|}
\hline 2 & $\begin{array}{l}\text { User } \\
\text { Menunggu } \\
\text { sampai } \\
\text { menu } \\
\text { utama } \\
\text { tampil } \\
\text { ketika } \\
\text { pertama } \\
\text { kali aplikasi } \\
\text { di jalan } \\
\text { setelah } \\
\text { splash } \\
\text { screen } \\
\end{array}$ & $\begin{array}{l}\text { Tampilan } \\
\text { aplikasi setelah } \\
\text { splash screen } \\
\text { dimana pada } \\
\text { halaman ini } \\
\text { terdapat menu } \\
\text { AR } \quad \text { Scan, } \\
\text { About, dan Help }\end{array}$ & $\begin{array}{l}\text { Halaman menu } \\
\text { utama dapat } \\
\text { tampil ketika } \\
\text { halaman splash } \\
\text { screen selesai. }\end{array}$ & $\begin{array}{l}\text { Sesuai } \\
\text { Harapan } \\
\text { (Valid) }\end{array}$ \\
\hline 3 & $\begin{array}{l}\text { User } \\
\text { memilh } \\
\text { menu AR } \\
\text { Scan di } \\
\text { menu utama }\end{array}$ & 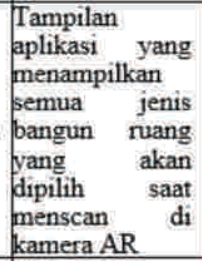 & $\begin{array}{l}\text { Halaman AR Scan } \\
\text { Tertampilkan dan } \\
\text { terdapat semua } \\
\text { jenis bangun } \\
\text { rang yang akan } \\
\text { di scan }\end{array}$ & $\begin{array}{l}\text { Sesuai } \\
\text { Harapan } \\
\text { (Valid) }\end{array}$ \\
\hline 4 & \begin{tabular}{|l} 
User \\
memilih \\
salah satu \\
jenis \\
bangun \\
ruang yang \\
ingin di \\
scan yang \\
pertama \\
Tabung
\end{tabular} & $\begin{array}{l}\text { Tampilan } \\
\text { aplikasi yang } \\
\text { menampilkan } \\
\text { kamera AR } \\
\text { aktif disebelah } \\
\text { kanan untuk } \\
\text { melakukan scan } \\
\text { marker yang } \\
\text { sudah kita } \\
\text { sediakan lalu } \\
\text { disebelah kiri } \\
\text { terdapat } \\
\text { deskripsi } \\
\text { bangun ruang } \\
\text { Tabung } \\
\end{array}$ & $\begin{array}{l}\text { Halaman Tabung } \\
\text { tertampilkan dan } \\
\text { kamera Ar scan } \\
\text { dapat menscan } \\
\text { marker dan gambar } \\
\text { 3D Tabung } \\
\text { tertampilkan }\end{array}$ & $\begin{array}{l}\text { Sesuai } \\
\text { Harapan } \\
\text { (Valid) }\end{array}$ \\
\hline 5 & \begin{tabular}{|l} 
User \\
memilih \\
salah satu \\
jenis \\
bangun \\
ruang yang \\
ingin di \\
scan yang \\
Kubus
\end{tabular} & $\begin{array}{l}\text { Tampilan } \\
\text { aplikasi yang } \\
\text { menampilkan } \\
\text { kamera AR } \\
\text { aktif disebelah } \\
\text { kanan untuk } \\
\text { melakukan scan } \\
\text { marker yang } \\
\text { sudah kita } \\
\text { sediakan lalu } \\
\text { disebelah kiri } \\
\text { terdapat } \\
\text { deskripsi } \\
\text { bangun ruang } \\
\text { Kubus } \\
\end{array}$ & $\begin{array}{l}\text { Halaman Tabung } \\
\text { tertampilkan dan } \\
\text { kamera Ar scan } \\
\text { dapat menscan } \\
\text { marker dan gambar } \\
\text { 3D Kubus } \\
\text { tertampilkan }\end{array}$ & $\begin{array}{l}\text { Sesuai } \\
\text { Harapan } \\
\text { (Valid) } \\
\end{array}$ \\
\hline 6 & \begin{tabular}{|l} 
User \\
memilih \\
salah satu \\
jenis \\
bangun \\
ruang yang \\
ingin di \\
scan yang \\
Balok
\end{tabular} & $\begin{array}{l}\text { Tampilan } \\
\text { aplikasi yang } \\
\text { menampilkan } \\
\text { kamera aktif } \\
\text { disebelah kanan } \\
\text { untuk } \\
\text { melakukan scan } \\
\text { marker yang } \\
\text { sudah kita } \\
\text { sediakan lalu } \\
\text { disebelah kiri } \\
\text { terdpat } \\
\text { deskripsi } \\
\text { bangun ruang } \\
\text { Balok }\end{array}$ & $\begin{array}{l}\text { Halaman Tabung } \\
\text { tertampilkan dan } \\
\text { kamera Ar scan } \\
\text { dapat menscan } \\
\text { marker dan gambar } \\
\text { 3D Balok } \\
\text { tertampilkan }\end{array}$ & $\begin{array}{l}\text { Sesuai } \\
\text { Harapan } \\
\text { (Valid) }\end{array}$ \\
\hline 7 & \begin{tabular}{|l} 
User \\
memilih \\
salah satu \\
jenis \\
bangun \\
ruang yang \\
ingin di \\
scan yang \\
Kerucut
\end{tabular} & $\begin{array}{l}\text { Tampilan } \\
\text { aplikasi yang } \\
\text { menampilkan } \\
\text { kamera aktif } \\
\text { disebelah kanan } \\
\text { untuk } \\
\text { melakukan scan } \\
\text { marker yang } \\
\text { sudah kita } \\
\text { sediakan lalu } \\
\text { disebelah kiri } \\
\text { terdpat } \\
\text { deskripsi } \\
\text { bangun ruang } \\
\text { Kerucut } \\
\end{array}$ & $\begin{array}{l}\text { Halaman Tabung } \\
\text { tertampilkan dan } \\
\text { kamera Ar scan } \\
\text { dapat menscan } \\
\text { marker dan gambar } \\
\text { 3D Kerucut } \\
\text { tertampilkan }\end{array}$ & $\begin{array}{l}\text { Sesuai } \\
\text { Harapan } \\
\text { (Valid) }\end{array}$ \\
\hline
\end{tabular}

\begin{tabular}{|c|c|c|c|c|}
\hline 8 & $\begin{array}{l}\text { User } \\
\text { memilih } \\
\text { salah satu } \\
\text { jenis } \\
\text { bangun } \\
\text { ruang yang } \\
\text { ingin di } \\
\text { scan yang } \\
\text { Limas }\end{array}$ & $\begin{array}{l}\text { Tampilan } \\
\text { aplikasi yang } \\
\text { menampilkan } \\
\text { kamera aktif } \\
\text { disebelah kanan } \\
\text { untuk } \\
\text { melakukan scan } \\
\text { marker yang } \\
\text { sudah aita } \\
\text { sediakan lalu } \\
\text { disebelah kiri } \\
\text { terdpat } \\
\text { deskripsi } \\
\text { bangun ruang } \\
\text { Limas }\end{array}$ & $\begin{array}{l}\text { Halaman Tabung } \\
\text { tertampilkan dan } \\
\text { kamera Ar scan } \\
\text { dapat menscan } \\
\text { marker dan gambar } \\
\text { 3D Limas } \\
\text { tertampilkan }\end{array}$ & $\begin{array}{l}\text { Sesuai } \\
\text { Harapan } \\
\text { (Valid) }\end{array}$ \\
\hline 9 & $\begin{array}{l}\text { User } \\
\text { memilih } \\
\text { salah satu } \\
\text { jenis } \\
\text { bangun } \\
\text { ruang yang } \\
\text { ingin di } \\
\text { scan yang } \\
\text { Bola }\end{array}$ & $\begin{array}{l}\text { Tampilan } \\
\text { aplikasi yang } \\
\text { menampilkan } \\
\text { kamera aktif } \\
\text { disebelah kanan } \\
\text { untuk } \\
\text { melakukan } \\
\text { marker yan } \\
\text { sudah rang } \\
\text { sediakan lalu } \\
\text { disebelah } \\
\text { terdpat } \\
\text { deskripsi } \\
\text { bangun ruang } \\
\text { Bola }\end{array}$ & $\begin{array}{l}\text { Halaman Tabung } \\
\text { tertampilkan dan } \\
\text { kamera Ar scan } \\
\text { dapat menscan } \\
\text { marker dan gambar } \\
\text { 3D Bola } \\
\text { tertampilkan }\end{array}$ & $\begin{array}{l}\text { Sesuai } \\
\text { Harapan } \\
\text { (Valid) }\end{array}$ \\
\hline 10 & $\begin{array}{l}\text { User } \\
\text { memilih } \\
\text { salah satu } \\
\text { jenis } \\
\text { bangun } \\
\text { ruang yang } \\
\text { ingin di } \\
\text { scan yang } \\
\text { Prisma }\end{array}$ & $\begin{array}{l}\text { Tampilan } \\
\text { aplikasi yang } \\
\text { menampilkan } \\
\text { kamera aktif } \\
\text { disebelah kanan } \\
\text { untuk melakukan } \\
\text { scan marker } \\
\text { yang sudah kita } \\
\text { sediakan lalu } \\
\text { disebelah kiri } \\
\text { terdpat deskripsi } \\
\text { bangun ruang } \\
\text { Prisma }\end{array}$ & $\begin{array}{l}\text { Halaman Tabung } \\
\text { tertampilkan dan } \\
\text { kamera Ar scan } \\
\text { dapat menscan } \\
\text { marker dan gambar } \\
\text { 3D Prisma } \\
\text { tertampilkan }\end{array}$ & $\begin{array}{l}\text { Sesuai } \\
\text { Harapan } \\
\text { (Valid) }\end{array}$ \\
\hline 11 & $\begin{array}{l}\text { User } \\
\text { memilh } \\
\text { menu } \\
\text { About pada } \\
\text { menu } \\
\text { utama }\end{array}$ & $\begin{array}{l}\text { Tampilan } \\
\text { aplikasi yang } \\
\text { menampilkan } \\
\text { deskripsi } \\
\text { tentang sekolah } \\
\text { SD anugrah } \\
\text { plus pekanbaru }\end{array}$ & \begin{tabular}{|l|} 
Halaman About \\
Tertampil dan \\
terdapat \\
penjelasan tentang \\
SD anugrah plus \\
pekanbaru
\end{tabular} & $\begin{array}{l}\text { Sesuai } \\
\text { Harapan } \\
\text { (Valid) }\end{array}$ \\
\hline 12 & $\begin{array}{l}\text { User } \\
\text { memilh } \\
\text { menu Help } \\
\text { pada } \\
\text { tampilan } \\
\text { menu } \\
\text { utama }\end{array}$ & $\begin{array}{l}\text { Tampilan } \\
\text { aplikasi yang } \\
\text { menampilkan } \\
\text { deskripsi } \\
\text { panduan } \\
\text { penggunaan } \\
\text { aplikasi AR } \\
\text { bangun ruang }\end{array}$ & $\begin{array}{l}\text { Halaman Help } \\
\text { tertampil, } \\
\text { menampilkan } \\
\text { semua tata cara } \\
\text { penggunaan } \\
\text { aplikasi }\end{array}$ & $\begin{array}{l}\text { Sesuai } \\
\text { Harapan } \\
\text { (Valid) }\end{array}$ \\
\hline
\end{tabular}

Berdasarkan dari hasil pengujian black box diatas, maka aplikasi implementasi augmented reality sebagai media pembelajaran bangun ruang berbasis android dapat digunakan oleh SD Anugrah Plus Pekanbaru sebagai media baru pembelajaran bangun ruang di sekolah kepada siswa.

\section{Deployment (Delivery, Support, Feedback)}

Deployment merupakan tahapan implementasi aplikasi implementasi augmented reality sebagai media pembelajran bangun ruang berbasis android kepada SD Anugrah Plus Pekanbaru agar dapat langsung di gunakan oleh guru dan siswa ketika proses pembelajaran berlangsung. Pemeliharaan aplikasi secara berkala. Perbaikan aplikasi akan dilakukan jika ada fiturfitur tidak berfungsi sesuai tujuan aplikasi dan ini sejalan dengan langkah evaluasi aplikasi. Pengembangan aplikasi akan dilakukan secara berakala setiap satu semester disesuaikan dengan kebutuhan pembelajaran di SD Anugrah Plus Pekanbaru dan 
perkembangan teknologi informasi dan komunikasi.

Selanjutnya umpan balik (feedback) yang bertujuan agar aplikasi dapat tetap berjalan dan berkembang sesuai dengan fungsinya. Umpan balik (feedback) ini diberikan oleh pengguna aplikasi dengan mengisi kuesioner penilaian, dari penilaian kuesioner tersebut pengguna memberikan penilaian tentang kemudahan menggunakan aplikasi 92\%, ini berarti aplikasi mudah digunakan, untuk manfaat bagi siswa didapat nilai $96 \%$, dengan arti aplikasi sangat bermanfaat bagi siswa. Kemudahan guru dalam menjelaskan tentang bagun ruang di dapat nilai $86 \%$, selanjutnya untuk tampilan aplikasi, pengguna memberikan penilaian $80 \%$ bahwa tampilan aplikasi menarik. Penilai tentang kelengkapan fitur aplikasi pengguna memberikan $80 \%$ yang berarti bahwa fitur aplikais cukup lengkap.

\section{HASIL \& PEMBAHASAN}

Hasil dan pembahasan merupakan tampilan dari aplikasi implementasi augmented reality sebagai media pembelajaran bangun ruang berbasis android kepada SD Anugrah Plus Pekanbaru yang telah selesai dibagun, dan telah diimplementasikan serta telah di build sebagai sebuah aplikasi android, berikut tampilan dari aplikasi tersebut:

1. Tampilan installasi aplikasi

Sebelum aplikasi digunakan oleh guru dan siswa aplikasi yang sudah di build sebagai aplikasi android diinstall terlebih dahulu di smartphone guru, berikut tampilan ketika proses diinstallasi:

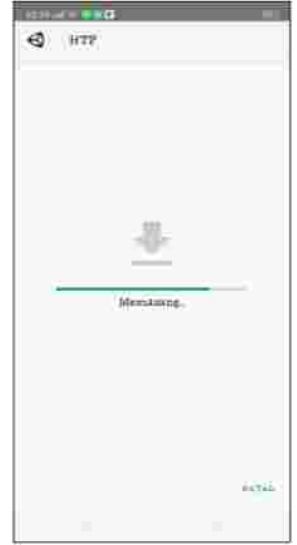

Gambar 6. Proses Installasi Apk

\section{Tampilan Menu Utama}

Tampilan menu utama ini merupakan halaman awal aplikasi yang terdiri dari AR Scan, About, Help, dan Kuis. Satu hal yang perlu diperhatikan pada aplikasi implementasi augmented reality sebagai media pembelajaran bangun ruang berbasis android ini adalah tampilan ketika aplikasi berjalan di smartphone hanya bisa dengan tampilan landscap (berbaring), aplikasi tidak bisa menampilkan tampilan secara portrait (berdiri). Berikut tampilan menu utama aplikasi implementasi augmented reality sebagai media pembelajaran bangun ruang berbasis android:

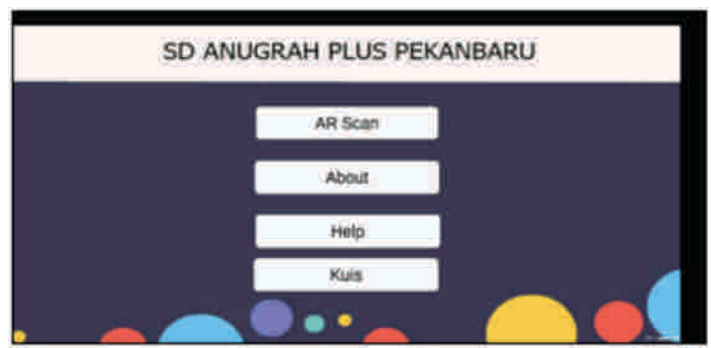

Gambar 7. Tampilan Menu Utama

3. Tampilan Menu Augmented Reality Bangun Ruang

Tampilan menu augmented reality bangun ruang ini menampilkan daftar nama-nama dari bangun ruang yang terdiri dari Tabung, Kubus, Kerucut, Prisma, Limas, Bola dan Balok. Adapun tampilan menu augmented reality bangun ruang pada gambar 8 berikut:

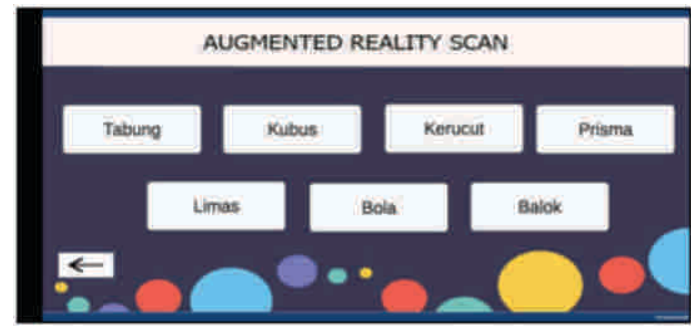

Gambar 8. Tampilan Menu Augmented Reality Bangun Ruang

Pada tampilan menu augmented reality bangun ruang di atas guru atau siswa bisa memilih salah satu dari bangun ruang tersebut untuk melihat gambar 3Dimensi-nya, jika telah memilih, guru atau siswa bisa mengarahkan kamera smartphone ke marker yang telah disiapkan, dan perlu diingat bahwa marker tesebut sebelum telah diinputkan dan didaftarkan ke aplikasi vuforia, yang mana sebagai contoh peneliti menampilkan hasil scan marker sebuah bola, hasilnya dapat dilihat pada gambar berikut:

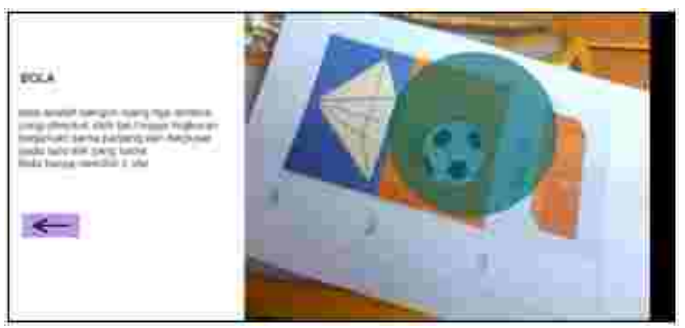

Gambar 9. Tampilan Hasil Scan Salah Satu Marker Bangun Ruang dengan Augmented Reality

4. Tampilan Menu Help

Tampilan Menu help berfungsi jika pengguna belum mengetahui cara penggunaan aplikasi implementasi augmented reality sebagai media pembelajaran bangun ruang berbasis android ini. 


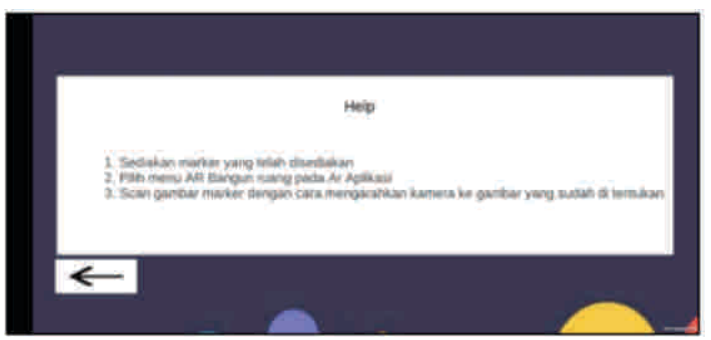

Gambar 10. Tampilan Menu Help

5. Tampilan Menu About

Tampilan menu about ini berfungsi untuk menjelaskan tentang aplikasi ini:

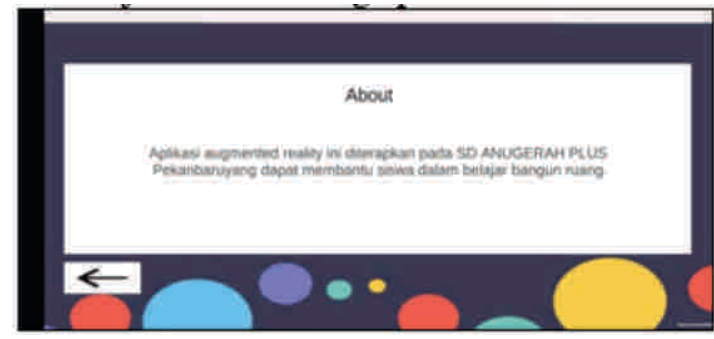

Gambar 11. Tampilan Menu About

6. Tampilan Menu Kuis

Gambar berikut adalah tampilan menu kuis aplikasi implementasi augmented reality sebagai media pembelajaran bangun ruang berbasis android yang berfungsi sebagai uji pengetahuan siswa terhadap bangun ruang, yang telah dipelajari dan dijelaskan oleh guru, berikut tampilan menu kuis (salah satu soal kuis):

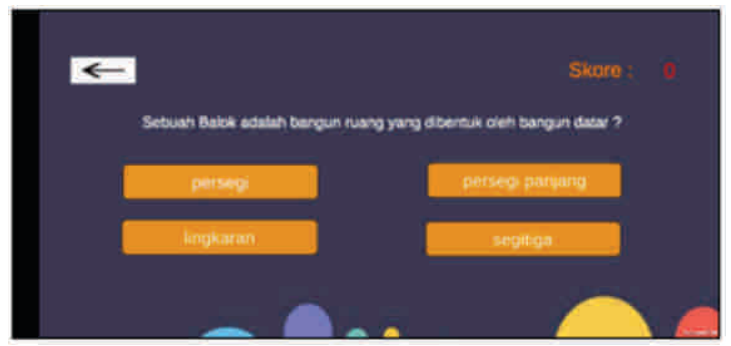

Gambar 12. Tampilan Menu Kuis (Salah Satu Soal Kuis)

\section{KESIMPULAN DAN SARAN}

Kesimpulan penelitian implementasi augmented reality sebagai media pembelajaran bangun ruang berbasis android ini yang mengacu pada rumusan masalah dan tujuan yang dapat disimpulkan beberapa hal diantaranya adalah sebagai berikut:

1. Aplikasi implementasi augmented reality sebagai media pembelajaran bangun ruang berbasis android mudah dimengerti dan digunakan. Hal ini dapat dilihat dari penilaian yang diberikan melalui kuesioner dengan nilai 92\% (Sangat Baik), guru menilai aplikasi ini sangat mudah digunakan.

2. Aplikasi implementasi augmented reality sebagai media pembelajaran bangun ruang berbasis android memberikan manfaat bagi guru dan siswa dalam hal proses belajar dan mengajar, yang terlihat penilaian dari guru dengan nilai $96 \%$ (Sangat Baik) melalui kuesioner, dan guru menilai aplikasi ini memberikan manfaat lebih dalam proses belajar mengajar.
3. Aplikasi implementasi augmented reality sebagai media pembelajaran bangun ruang berbasis android memudahkan guru dalam menjelaskan bentuk bangun ruang secara real. Hal ini dapat dilihat dari kuesioner yang diberikan kepada guru bahwa 86\% (Sangat Baik), guru menilai aplikasi ini dapat digunakan saat menjelaskan bangun ruang secara real karena gambar bangun ruang disajikan secara 3 dimensi.

4. Aplikasi implementasi augmented reality sebagai media pembelajaran bangun ruang berbasis android bangun ruang sangat menarik dan fitur - fiturnya sangat lengkap. Hal ini dapat dilihat dari kuesioner yang diberikan kepada guru bahwa $80 \%$ (Sangat Baik) aplikasi bangun ruang ini sangat menarik dan $80 \%$ aplikasi AR memiliki fitur yang sudah lengkap, guru menilai aplikasi ini dapat digunakan karena visual yang menarik dan ditambah fitur yang sudah baik.

Sistem pembelajaran bangun ruang menggunakan teknologi augmented reality masih jauh dari kata sempurna, adapun saran untuk pengembangan agar aplikasi ini lebih optimal dan lebih menarik adalah:

1. Perbaikan dan penambahan pada objek 3D bangun ruang, yang bisa lebih baik dan lengkap lagi.

2. Penulis berharap, penjelasan mengenai macam-macam bentuk Bangun Ruang bisa ditampilkan lebih spesifik lagi

\section{DAFTAR PUSTAKA}

Adami, F. Z., \& Budihartanti, C. (2016). Penerapan Teknologi Augmented Reality Pada Media Pembelajaran Sistem Pencernaan Berbasis Android. Teknik Komputer AMIK BSI, 2(1), 122-131. Retrieved from http://ejournal.bsi.ac.id/ejurnal/index.php/jtk/artic le/viewFile/370/279

Budiman, H. (2017). Peran Teknologi Informasi Dan Komunikasi Dalam Pendidikan. Al-Tadzkiyyah: Jurnal Pendidikan Is I a m, 8(1), 31-43. https://doi.org/10.24042/atjpi.v8i1.2095

Bujuri, D. A. (2018). Analisis Perkembangan Kognitif Anak Usia Dasar dan Implikasinya dalam Kegiatan Belajar Mengajar. LITERASI (Jurnal Ilmu Pendidikan), 9(1), $\begin{array}{lllll}3 & 7 & - & 5 & 0\end{array}$ https://doi.org/10.21927/literasi.2018.9(1).37-50

Daeng, I. T. M., Mewengkang, N. N., \& Kalesaran, E. R. (2017). Penggunaan Smartphone Dalam Menunjang Aktivitas Perkuliahan Oleh Mahasiswa Fispol Unsrat Manado. Acta Diurna, VI(1), 1-15. Retrieved from https://ejournal.unsrat.ac.id/index.php/actadiurna komunikasi/article/view/15482/15023

Febiharsa, D., Sudana, I. M., \& Hudallah, N. (2018). Uji Fungsionalitas (BlackBox Testing) Sistem Informasi Lembaga Sertifikasi Profesi (SILSP) Batik Dengan AppPerfect Web Test Dan Uji Pengguna. JOINED Journal, 1(2), 117-126. 
https://doi.org/10.31331/joined.v1i2.752

Hanief, S., \& Masurya, I. M. N. (2014). Augmented Reality Book Pengenalan Busana Pernikahan Adat Bali Berbasis Multimedia. Jurnal Sistem Dan Informatika, 9(1), 52-62. Retrieved from https://www.jsi.stikombali.ac.id/index.php/jsi/article/view/37

Harususilo, Y. E. (2018). Wah, Siswa Indonesia Pemakai Teknologi Tertinggi Dunia! Ini 7 Faktanya. Retrieved $\mathrm{S}$ e $\mathrm{pte} \mathrm{m} \mathrm{b}$ e $\mathrm{r} 8, \quad 2020, \mathrm{from}$ https://edukasi.kompas.com/read/2018/12/11/08 143651/wah-siswa-indonesia-pemakai-teknologitertinggi-dunia-ini-7-faktanya?page=all

Havilluddin. (2011). Memahami Penggunaan UML ( Unified Modelling Language ). Jurnal Informatika Mulawarman, 6(1), 1-15. Retrieved from http://ejournals.unmul.ac.id/index.php/JIM/article/view/1 6

Kania, N. (2017). Efektivitas Alat Peraga Konkret Terhadap Peningkatan Visual Thinking Siswa. THEOREMS (The Original Research of Mathematics), 1(2), 64-71. https://doi.org/http://dx.doi.org/10.31949/th.v1i2. 350

Kridalaksana, A. H., Rangan, A. Y., \& Satria, B. (2016). Pembelajaran Bangun Ruang Berbasis Augmented Reality Dengan Metode Marker Augmented Reality. Sebatik Stmik Wicida, 15(1), 19-24. https://doi.org/https://doi.org/10.46984/sebatik.v $15 i 1.71$

Mahendra, I. B. M. (2016). Implementasi Augmented Reality (Ar) Menggunakan Unity 3D Dan Vuporia Sdk. Jurnal IImu Komputer, 9(1), 1-5. Retrieved from https://ojs.unud.ac.id/index.php/jik/article/view/2 6341

Masykur, R., Nofrizal, \& Syazali, M. (2017). Pengembangan Media Pembelajaran Matematika dengan Macromedia Flash. Al-Jabar : Jurnal Pendidikan $\mathrm{M}$ a t e m a ti ka , 8(2), 177-186. https://doi.org/10.24042/ajpm.v8i2.2014

Mulyanto, A. (2016). Pengujian Sistem Informasi Akademik Menggunakan Mccall's Software Quality Framework. Jurnal Informatika Sunan Kalijaga, 1(1), $\begin{array}{lllll}4 & 7 & - & 5 & 7\end{array}$. https://doi.org/http://dx.doi.org/10.14421/jiska.20 $16 . \% 25 x$

Mursyidah, \& Hidayat, H. T. (2017). Pengujian Sistem Informasi Akuntansi Biaya Operasional Sekolah Dengan Black Box Testing. Jurnal Info Media, 2(2), 7 https://doi.org/http://dx.doi.org/10.30811/.v2i2.5 12
Mustaqim, I., \& Kurniawan, N. (2017). Pengembangan Media Pembelajaran Berbasis Augmented Reality. Jurnal Edukasi Elektro, 1(1), 36-48. https://doi.org/https://doi.org/10.21831/jee.v1i1. 13267

Nincarean, D., Alia, M. B., Halim, N. D. A., \& Rahman, M. H. A. (2013). Mobile Augmented Reality: The Potential for Education. Procedia - Social and Behavioral Sciences, $103,657-664$. https://doi.org/10.1016/j.sbspro.2013.10.385

Pratama, A. R. (2019). Belajar Unified Modeling Language (UML). Retrieved September 11, 2020, from https://www.codepolitan.com/unified-modelinglanguage-uml

Pressman, R. S. (2012). Rekayasa Perangkat Lunak (Pendekatan Praktisi) (Ed.7). Yogyakarta: Andi.

Rahmayani, I. (2015). Indonesia Raksasa Teknologi Digital Asia. Retrieved September 8, 2020, from https://kominfo.go.id/content/detail/6095/indones ia-raksasa-teknologi-digital-asia/0/sorotan_media

Setiawan, D. (2017). Dampak Perkembangan Teknologi Informasi dan Komunikasi Terhadap Budaya. S I M B O L I K A, 4(1), 62-72. https://doi.org/10.1155/2015/146250

Simanjuntak, P., \& Kasnady, A. (2016). Analisis Model View Controller (MVC) pada Bahasa PHP. Jurnal ISD, 2(2), 56-6 6. R e t r i e ve d f r o m https://122.200.2.179/index.php/isd/article/view/ 80

Sukamto, R. A., \& Shalahuddin, M. (2013). Rekayasa Perangkat Lunak Terstruktur dan Berorientasi Objek. Bandung: Informatika.

Triandini, E., \& Suardika, I. G. (2012). Step by Step Desain Proyek Menggunakan UML. Yogyakarta: Andi.

Tunarso, R., Setiawan, A., \& Santoso, L. W. (2017). Analisa Migrasi Sistem Dari Microsoft Dynamics Axapta. Jurnal Infra, 5(1), 199-204. Retrieved from http://publication.petra.ac.id/index.php/teknikinformatika/article/view/5159 